\title{
Correction to: Linking Availability Expectations, Bidirectional Boundary Management Behavior and Preferences, and Employee Well-Being: an Integrative Study Approach
}

\author{
Kathrin Reinke ${ }^{1,2} \cdot$ Gisela I. Gerlach $^{3}$
}

Published online: 6 November 2021

๑) Springer Science+Business Media, LLC, part of Springer Nature 2021

\section{Correction to: Journal of Business and Psychology} https://doi.org/10.1007/s10869-021-09768-x

There was an error in the references in the electronic supplementary material. The construct exhaustion should refer to Maslach, Jackson and Leiter (1996), and the correct year for Frone and Rice is 1987. A new corrected document has been uploaded.

Besides, there was a layout error in the Measures section of the original article. The original article has been corrected.

Supplementary Information The online version contains supplementary material available at https://doi.org/10.1007/s10869-021-09778-9.

Publisher's Note Springer Nature remains neutral with regard to jurisdictional claims in published maps and institutional affiliations.

The original article can be found online at https://doi.org/10.1007/ s10869-021-09768-x.

Kathrin Reinke

kathrin.reinke@tu-darmstadt.de

1 Institute of Psychology, Technische Universitat Darmstadt, Darmstadt, Germany

2 Department of Business Psychology, University of Kassel, Kassel, Germany

3 Department of Economics, Universitat Koblenz-Landau, Landau, Germany 